\title{
Two Sides of the Same Story: Alcohol Use and HIV Risk Taking in South India
}

\author{
Daniela C. Rodríguez $\cdot$ A. K. Krishnan $\cdot$ N. Kumarasamy $\cdot$ \\ Gopal Krishnan · Davidson Solomon · Sethulakshmi Johnson • \\ C. K. Vasudevan · Raja Solomon • Maria L. Ekstrand
}

Published online: 11 June 2010

(C) The Author(s) 2010. This article is published with open access at Springerlink.com

\begin{abstract}
This qualitative study examines the role of alcohol in sexual risk among male migrant workers and female sex workers in two South Indian states. Most men reported using alcohol for increased energy and courage prior to their sexual experiences and to reduce feelings of loneliness and isolation. Sex workers, on the other hand, often stated that they avoided alcohol prior to sex in order to stay alert and reduce the risk of violence. Both groups reported that drinking often increased male aggression and reduced condom use. Research is needed to examine the prevalence of these patterns as well as factors associated with sexual risk and violence, in order to develop targeted interventions for these groups. Future risk reduction programs may benefit from addressing safer ways of meeting the needs expressed by the participants. This may include
\end{abstract}

D. C. Rodríguez · M. L. Ekstrand

School of Public Health, University of California,

Berkeley, CA, USA

A. K. Krishnan · N. Kumarasamy · S. Johnson ·

C. K. Vasudevan

Y.R. Gaitonde Centre for AIDS Research and Education,

Chennai, India

G. Krishnan

Shelter, Calicut, India

D. Solomon · R. Solomon

SHADOWS, Chirala, India

M. L. Ekstrand ( $\square)$

Center for AIDS Prevention Studies, University of California,

San Francisco, Suite 1350, 50 Beale St, San Francisco,

CA 94105, USA

e-mail: Maria.Ekstrand@ucsf.edu

M. L. Ekstrand

St John's Research Institute, Bangalore, India strategies to defuse volatile situations, safe ways of improving the sexual experience, and interventions aimed at alleviating loneliness and isolation for migrants.

Keywords Male migrant workers - Female sex workers · Alcohol $\cdot$ HIV risk-taking $\cdot$ India

\section{Introduction}

The Indian National AIDS Control Organization (NACO) estimates that 2.47 million people are living with HIV/ AIDS in India [1] and has determined that India is following a Type 4 Pattern of transmission in which the epidemic shifts from the most vulnerable populations, such as men who have sex with men (MSM), female sex workers (FSW) and injecting drug users (IDUs), to bridge populations like clients of sex workers, sexually-transmitted infection (STI) patients and partners of drug users [1]. As such, MSM, FSW and STI clinic attendees are population groups that have been of particular concern to public health officials [2].

The last two decades have seen changes in alcohol use patterns in developing countries that indicate an increase in alcohol consumption and its attendant problems [3-5]. A marker for these issues is the steady increase in the mid2000 s of alcohol sales in India at a rate of 7-8\% [6]. As in other developing countries, alcohol use in India is reported primarily by men with general population surveys showing a range of $23-74 \%$ lifetime alcohol consumption among men, while alcohol consumption among women in the general population has remained minimal at about $3 \%[3$, 7-16]. However, national surveys can be misleading because the results tend to mask significant regional and population variations [17]. A National Household Survey 
on Drug Use in India reported a nationwide prevalence of alcohol use among adults of $21 \%$. However, state prevalence rates ranged from $7 \%$ in Gujarat to $75 \%$ in Arunachal Pradesh [6, 18].

Research conducted in developed countries has demonstrated that alcohol consumption is linked to both sexual risk-taking and HIV infection [19-21]. A review of these studies [22-24] suggests that alcohol consumption in general, as well as drinking in potentially sexual situations, is associated with increased probability of intercourse, with unprotected sex, and with HIV infection. Some of these findings have been replicated in India. In Chennai, for example, alcohol consumption often was found to precede commercial sex and extra-marital sex among men frequenting wine shops $[25,26]$. Two Mumbai studies further found that men who consumed alcohol on a regular basis were more likely to engage in extra-marital sex [27].

\section{Potential Bridge Populations}

Research among Indian migrant men and female sex workers suggests higher prevalence of drinking and risktaking behaviors than in the general population. A study of male STI outpatients in Mumbai found that engaging in sex while under the influence of alcohol was associated with unprotected sex, having a greater number of sexual partners, and with an increased risk of being diagnosed with STIs, including HIV [28]. Further, a study of male migrant workers (MMW) in four Indian states found that over $75 \%$ of contract laborers reported alcohol use [29]. Seventeen percent of MMW in this study reported sex with a sex worker in the past year, but only $58 \%$ reported consistent condom use with all sex workers during the same period [29]. With respect to FSW, studies suggest that the prevalence of drinking among FSW is higher than among the general population of women in India [17, 30]. According to the latest National Behavioral Surveillance Survey by NACO, $46 \%$ of FSW reported that they had consumed alcohol in their lifetime. Of those, $11 \%$ reported that they drink "regularly" and $79 \%$ that they "sometimes" drink before having sex [31]. Currently, NACO does not report the prevalence of alcohol use among FSW by partner type. As for condom use, NACO estimates that $88 \%$ of FSW used a condom at their last sexual encounter with a paying client, but that only $54 \%$ used a condom the last time they had sex with a non-paying partner [31].

A recent study among clients of Mexican FSW on the border between the US and Mexico reported high proportions of risky behaviors, such as unprotected sex with a FSW and being under the influence of drugs during sex with a FSW, suggesting the clients' potential to serve as bridge population from high risk to low risk population groups [32]. Currently available data on alcohol use and sexual risk-taking in India are drawn from quantitative, correlational studies that do little to explain the contextual factors at play in the sexual interactions between female sex workers and their clients. Furthermore, there is very little research exploring the perspectives of both FSW and their clients when examining the role of alcohol and its relationship to sexual risk-taking during commercial sex. Data from both partners in a sexual exchange need to be incorporated into research and intervention programs as they provide more comprehensive contextual information about the motivations for sexual risk as well as protective behaviors [19, 20, 24, 33, 34]. This paper aims to meet this need by presenting data that describe the role that alcohol consumption plays in the commercial sex encounter between female sex workers and their male migrant worker clients by drawing on information garnered through qualitative interviews with both partner groups. The data presented in this paper are drawn from the formative qualitative phase preceding a larger quantitative research project that aims to gain a better understanding of HIV risk-taking in the context of alcohol consumption among MMW and FSW in South India.

\section{Methods}

\section{Study Setting}

The sites for this study are the towns of Chirala, Andhra Pradesh and Calicut, Kerala. This project is taking place in partnership with three non-governmental organizations in South India: Y.R. Gaitonde Centre for AIDS Research and Education (YRGCARE) in Chennai, providing data coordination, training and supervision, as well as SHADOWS in Chirala and Shelter in Calicut, who were responsible for all field work. Social mapping was conducted by trained personnel at both study sites and included observations of local hang-outs for both partner groups and population counting. Findings were confirmed with key informant interviews with both population groups at both sites.

Chirala is a town of half a million inhabitants in the Prakasham district of Andhra Pradesh (AP). Farming of tobacco and chili and weaving are primary sources of employment. The town is part of coastal AP, thus fishing is a common occupation for many men. Chirala's economic links to textile and tobacco industries attract business visitors and migrant workers, both of which contribute to a large sex industry. This is exacerbated by significant trucking traffic through the region where FSW establish themselves at truck stops making them sex-trading locations. Social mapping indicates that other cruising areas include wine and tea shops, cinema theaters, and railway and bus stations. NACO has designated AP a high 
prevalence state as indicated by a $22 \%$ HIV prevalence at STI surveillance sites and greater than $1 \%$ at antenatal care (ANC) sites [35]. Prakasham district has an HIV prevalence of $37 \%$ at STI surveillance sites and $4 \%$ among FSW, which makes it a high prevalence district [36]. According to NACO, over $40 \%$ of FSW in Andhra Pradesh report consuming alcohol in their lifetime [31]. Of those, $98 \%$ state that they regularly or sometimes drink before having sex [31]. A study of migrant men found that $85 \%$ of laborers in Andhra Pradesh reported alcohol use in the last month, and $40 \%$ reported alcohol use before having sex with a sex worker or unpaid, non-marital partner in the last year [29]. Furthermore, more than $30 \%$ of laborers reported sex with a sex worker in the last 12 months, but only $43 \%$ reported consistent condom use with all sex workers during the same period placing them at significant risk for infection with HIV and other STIs [29].

Calicut, recently renamed Kozhikode, is a town of over 400,000 inhabitants in northern Kerala state. Kerala has been designated a moderate HIV prevalence state; however Calicut is considered a high prevalence site among ANC clinic attendees [37]. Furthermore, according to NACO, the most recent data for Calicut indicate 1.9 and $4.6 \% \mathrm{HIV}$ prevalence among STI clinic attendees and FSW, respectively [38]. Forty-eight percent of FSW in Kerala report having consumed alcohol in their lifetime, and $82 \%$ stated that they regularly or sometimes engage in drinking before sex [31]. ${ }^{1}$ Calicut is a business hub and popular tourist destination located between the Arabian Sea and the Wayanad Hills. Many migrants come to Calicut from other parts of Kerala as well as from other states; most are from Tamil Nadu. Compared to other districts in Kerala, Calicut offers more job opportunities at higher wages due to the presence of strong unions. Migrants tend to work in construction, industries, bank and sales jobs. The social mapping conducted as part of this study confirmed this and determined that the main cruising spots for MMW and FSW in Calicut include public spaces, such as public squares, roads, railway and bus stations, and shopping malls. We also discovered that persons in the high and upper middle classes often engage sex workers through pimps and brokers.

\section{Methods}

Participants were referred by key informants and through snowball sampling to SHADOWS and Shelter, making a special effort to include participants from all categories of migrant men in the region and all different types of sex workers, whenever possible. Eligibility criteria for the qualitative phase included being at least 18 years old,

\footnotetext{
${ }^{1}$ For Kerala the estimates also include Lakshadweep.
}

living in or around one of the study cities, and speaking one of the local languages. Female sex workers had to have engaged in sex work for at least 3 months at the study site and male migrant workers had to have been migrant workers in one of the study sites for at least 3 months. The analysis in this paper is based on interviews with $38 \mathrm{MMW}$ (15 and 23 from Chirala and Calicut, respectively) and 63 FSW (35 and 28 from Chirala and Calicut, respectively).

All of the migrant workers included in the analyses reported a history of commercial sex with a FSW in the region. Only one migrant worker was excluded from the analyses, due to reporting exclusive sexual activity with other men. Although we were not able to match individual clients and sex workers, due to confidentiality issues, the participants included in these analyses reported frequenting the same sites in the community for solicitation and pick up, suggesting that they belong to the same sexual networks. They also represent the same socioeconomic groups as the general groups of migrant men and sex workers, who were observed at these sexual pick-up sites by our observers during the social mapping phase of this study.

A semi-structured qualitative interview guide was developed that included questions about patterns of alcohol and drug use, patterns and context of sexual behaviors, motivations for different sexual practices, and perceptions of gender-roles for men and women. Participants provided informed consent prior to the interview. Face-to-face interviews were conducted in private spaces, including study offices, empty rooms in lodges, in isolated public spaces and in our project jeep. The interviewers were provided extensive training in interviewing skills, HIV, the study protocol, and research ethics. Interviews lasted between 30 and $90 \mathrm{~min}$ and were audio-recorded and transcribed verbatim in the local languages. After the interview, participants received a reimbursement of Rs 150 (about \$3 USD) for their time and transportation expenses. This study was approved by the Committee on Human Research at the University of California, San Francisco, by the Institutional Review Board at YRGCARE Chennai, India and received clearance by the Indian Council for Medical Research (ICMR). Following removal of all identifiers, the transcripts were translated into English.

Four investigators, representing both Indian and US investigators, read through all of the transcripts. Prior to reading the interviews, the readers agreed on the themes of alcohol use, commercial sex encounters and violence with sexual partners, for the purpose of this paper. Initial coding was completed by a primary coder, with subsequent review by a secondary coder. If any new code related to the three themes emerged during the reading of transcripts, it was discussed and consensus was reached between all of the readers prior to adding the new code. This process continued until agreement was reached on the final 35 codes 
and sub-codes, at which point all readers re-read and applied these codes until consensus was achieved. The patterns of responses were analyzed manually and responses between respondent groups and study sites were compared. In the reporting of results, proportions are used for illustrative purposes with reference to the study sample only, and is not intended to generalize to the larger populations from which the study samples are drawn.

\section{Results}

Themes are presented in two components: alcohol use motivations and consequences of alcohol use from the perspectives of both the FSW and MMW. As will be demonstrated, the perspectives of male and female participants included both similar and different views on these two topics. In the first two sections, we present areas in which there was consistency in the experiences reported from the two field sites. A third section subsequently describes two key areas in which the data were sitespecific.

\section{Alcohol-Related Motivations}

Both MMW and FSW reported using alcohol before engaging in commercial sex, but their motivations varied. Three-quarters of the MMW interviewed reported using alcohol prior to seeking out FSW for sex. They reported a number of expected positive outcomes from drinking alcohol, such as getting them in the mood for sex, providing them with more energy to last longer during sex, and improving their sexual satisfaction. Two-thirds of participants also felt that without alcohol they would not be bold enough to seek out sex outside of their primary relationships or to ask for non-traditional sexual positions.

If we go for sex without drinking, we will not have the energy. But we will feel energetic after drinking. I drank when I had sex with that lady [last partner] and also with those two sex workers.-Male migrant worker Calicut

We have boldness when we drink, we will have the feeling that we should ask and say something, I will think to keep a woman for me... When I don't drink I will not have the thought of having sex with a woman but when I drink I will have the feeling.-Male migrant worker Chirala

When having [sex] with sex workers, we will have more experiences and we will also have good experiences.-Male migrant worker Calicut
R: If I go for sex without drinking, I feel we are doing a mistake.

I: So, do you drink before sex, to avoid those feelings?

R: Of course, only then can I engage in sex freely and get more satisfaction... Of course, I get more satisfaction when I consume alcohol. If we have a drink we wouldn't know what's going around and we got more satisfaction in sex.-Male migrant worker Chirala

To have sex I will have drinks, I cannot control myself. If I don't drink nothing works out.-Male migrant worker Chirala

MMW also reported that alcohol use eased their emotional discomfort and made them feel less lonely, making them more likely to seek out FSW.

When we drink we get sexual feelings. Sometimes we feel lonely and sad. Some of them [other MMW] feel that because they do not have a wife. So, they participate in sex for satisfaction [with FSW].-Male migrant worker Chirala

While less than a quarter of FSW reported using alcohol around their commercial sex encounters, about half reported specifically avoiding alcohol use before sex, even if they were regular drinkers at other times, out of fear of losing control during the sexual encounter. Of those who did report drinking before sex, about a third reported that they would drink before sex to self-medicate in order to numb themselves, so they wouldn't be aware of what was happening around them. One participant, however, perceived that alcohol had more explicit medicinal qualities:

Previously I was taking toddy, which is good for your health...I tell all the sex workers to drink toddy. The heat of the males while having sex will be transferred to us, so this toddy will give coldness, so I am drinking toddy.-Female sex worker Chirala

Of those FSW who did not drink around commercial sex, half stated that this was because they wanted to avoid difficult situations such as violent exchanges or being cheated by clients. Three quarters of the FSW reported fear that clients would become aggressive and they would be unable to flee. A third of the FSW wanted to maintain full control of their senses in order to avoid getting tricked by clients who would demand different types of sex, avoid or reduce payment, or avoid using condoms.

I didn't drink because I got fear. I got frightened that the clients will cheat me because we will not know in which stage we are and they will not use condoms and if he has sex, we don't know what disease he could have and if it gets transmitted; this is the 
fear...Let him have drinks but I have to be good so I will not drink, I will use condoms for having sex.Female sex worker Chirala

We should be alert when we are with the clients, they may do anything to us. We shouldn't regret it later... If I drink with a client they will compel us to do sex in whatever ways they like. That is why I am not taking drinks, when I am there with clients... I'll tell to those I know that, there is no problem in drinking, but we should not drink when we are with clients.Female sex worker Calicut

In spite of their intentions to avoid alcohol, FSW did report being forced on occasion to drink by their clients who were also drinking.

I wasn't [drunk]. It wasn't a comfortable situation to drink...The client who I was with threatened me, that he would kill me. If I was drunk in that situation I wouldn't be able to escape from him. He had drinks and insisted I drink too. I didn't drink as the payment issue came up.-Female sex worker Calicut

\section{Two Sides of the Same Story}

An interesting paradox emerged from these interviews. MMW perceived the physical effects of alcohol to be beneficial during the sexual transaction and therefore sought them out. The FSW, on the other hand, reported disliking those same physical effects of alcohol and therefore avoided clients who were inebriated.

Specifically, MMW stated that they often drank before engaging in commercial sex because alcohol gave them the courage to seek out sex workers and it helped them last longer during the sexual encounter, as long as they didn't drink too much.

If we involve in sexual activity after alcohol consumption it is a voluntary activity that we perform actively with involvement...There will be delay in ejaculation when we have sex after alcohol consumption. But there will be quick ejaculation if we won't consume alcohol._-Male migrant worker Chirala

We will get more pleasure in sex after drinking. We can do sex for long time after drinking. "Udechanashakthi" [strength to perform sex] will increase... That is why we are drinking. If we consume alcohol more and more [i.e., heavy drinking], there will not be Udechanashakthi. Our penis will shrink.-Male migrant worker Calicut

In contrast, FSW reported disliking and avoiding inebriated clients for several reasons, reporting that clients who had been drinking took too long during the sexual encounter, preventing the women from finding other clients and thus limiting their potential income. In addition, they found that inebriated clients were often loud and aggressive, causing problems for the FSW with lodge owners as well as drawing attention from others.

After drinking some [clients] have beat us. Some have tried to steal the money. There were lots of conflicts, attacks and all. Others [other FSW] also talk about such experiences like quarrels and all... If that person goes to another lady we will show them signals through eyes which indicate don't go. We will not say it openly... Thus we will try to help others avoid the bad experience which we have suffered earlier.-Female sex worker Calicut

The client who does not take alcohol will do sex for few minutes and go off. But the drunkard client will involve in sex for two hours too and won't go out easily. These people will take much time and we can't manage that long.-Female sex worker Chirala

Well it's simple! If my client is a non-alcoholic one, we can finish the sex very fast and vacate the room [in the lodge]. But if he is an alcoholic it's difficult to vacate the room fast. That is because he will take lot of time to complete the sex-Female sex worker Calicut

These reports suggest that both MMW and FSW attempted to maximize their gains from the sexual transaction. In contrast, MMW would drink prior to sex in order to last longer during the encounter and "get their money's worth". FSW disliked inebriated clients and avoided them whenever possible because they were less compliant with FSW instructions, more difficult to manage in public settings, and could take up too much of the FSW's time.

\section{Consequences of Alcohol Consumption}

MMW and FSW described a variety of behaviors that clients engaged in when inebriated. Both sets of participants reported that clients were more likely to request different types of sex after they had been drinking. Specifically, clients requested specific sexual acts that they had seen in pornographic (or "blue") films. MMW in particular reported that these different types of sex were ones that they could request from FSW but not from their wives. While FSW may have felt pressured to yield to their requests, both parties seemed to be aware that the clients would be charged more for non-traditional sexual positions. 
Of course I like sex when I have a drink because at that time it gives me more satisfaction. Sometimes we ask the sex workers to engage in sex in some positions for more satisfaction but they didn't agree to do like that. If we force they demand excess money from us. We get different thoughts when are under the influence of alcohol and they differ when we didn't drink. -Male migrant worker Chirala

I cannot have sex with my wife like the sex which I have the other sexual workers. While having sex outside [with an FSW], I will have sex as I wish but likewise I cannot have sex with my wife.-Male migrant worker Chirala

They [drunk clients] will say to bend, will say to stand, they will say to do all sorts of things... They will say to see blue films cassettes and will say to have sex that way...During that time I will ask more money...I will ask 500 to 600 rupees.-Female sex worker Chirala

Clients also appeared more likely to behave aggressively when inebriated. Male and female participants reported that the men forced FSW to engage in sex, fondled the women violently, and refused to use condoms after drinking. Similarly, FSW reported that inebriated clients could act out so loudly as to attract the attention of other parties, including the police.

I like sex after drinking because when I have a drink I get more satisfaction. So, every time we go outside after drinking... We sometimes force them [FSW] to have sex in different positions. Sometimes they tell us to stop.-Male migrant worker Chirala

If we hesitate to go with them [drinkers] then they physically carry me to some corner and will compel me to do sex with their friends. After that they will give money, sometimes they don't. I want to save my life so I'll agree to do that.-Female sex worker Calicut

The persons who are under the influence of alcohol won't listen to what we are saying and act as they wish and also force us to obey their words. But the persons who are not taken alcohol will consider what we say. We have been beaten by drunkard clients. There so many such experiences. Rowdies will also come at that time we can't do anything and we have to obey their words.-Female sex worker Chirala

I will not allow them if they come by having more drinks. I will send them out. They will say that they are going to consume alcohol before having sex but I will not accept them to have sex. If suppose, if he buys and has here, he will act as rowdy and the police may come, create a problem and where will I run?Female sex worker Chirala

\section{Condom Use and Alcohol Consumption}

Both male and female participants reported that condom use was influenced by the availability of a condom immediately prior to the sexual act itself. Two-thirds of the FSW reported that they carried condoms with them whenever they meet clients, and a quarter of the MMW also reported carrying or buying a condom before engaging in commercial sex. Of particular concern were the reports from participants that they had used more than one condom at a time during a sexual act as a way to ensure greater protection.

I: Did you use any preventive measures like condoms and all while having sex with her?

R: No. The reason was that it [sexual act] just happened. I got the chance to have sex with that lady. In that situation one will not go to buy a condom. At that time I did not think about any diseases and I was very much interested in having sex.-Male migrant worker Calicut

Some clients ask; do you have condom? I told them yes I have condom with me. Some clients told me they don't like to use condom, then I replied I don't like to do sex without using condom. Good clients always prefer sex with condom.-Female sex worker Calicut

Sex workers give condoms to us when we go there.

But we ask for 2 or 3 condoms for more protection.

Because nowadays the society is suffering with HIV,

AIDS so we take maximum care during these

times.-Male migrant worker Chirala

Not surprisingly, the likelihood of using condoms was lower if one or both of the partners had been drinking. Any initial reluctance from clients to use condoms was reinforced if they had been drinking, occasionally resulting in physical violence towards the FSW. When dealing with these clients, FSW developed creative strategies to try to convince them to use condoms. A quarter of the women tried verbal tactics such as appealing to the clients' desire to protect their families from any misfortune or by attempting to elicit sympathy for the FSW's situation. A few attempted a physical solution by offering to manually stimulate the client instead of performing intercourse.

I: Some men are reluctant to use condoms when they are under the influence of alcohol. Have you had any similar experiences? 
R: Yes, they do but even though they put on the condom, they will try to remove it or tear it off when engaging in sex. I am very careful with these clients. Some of them have even physically abused me for questioning their condom use...It happened four months back, a client took me. He was very reluctant to use a condom, he also had a lump in his pubic area, I was afraid after seeing this. I forcefully put the condom on him and he removed it all the time. When I didn't budge, he hit me in my face.-Female sex worker Calicut

If a condom is not there, we will tell our customers we have no time for you. Otherwise we tell our customers we will hold your penis with our hands and shake it or we will place it on our thigh; without condoms we will never ever allow you to have sex with us. We also tell them if you don't have [a condom]we will provide you with one, then we take out a condom and give it them, we also tell them that we have kept one in the bag and we will give you one, and they say, you are doing business by keeping a packet of condoms with you. Then we say of course this is what we do, or else our business won't flourish. If at all our stomach bulges out and if we come to your place, will you accept us, or avoid us when seeing us in that situation?-Female sex worker Calicut

Some will ask for condom even if they are drunk. They will ask "do you have Nirodh [government brand of condoms, term used to represent all condoms]?" I will tell them that I am going with several people and I cannot know whether I have any disease... If I have any diseases you will also become in trouble. You have your own family and all... like this. I will tell all the matters to them.-Female sex worker Calicut

Both the lady and I did not have condoms with us. I was not aware about the usage of condoms. But that lady had condoms with her. I asked her why we are using it. She made me understand.-Male migrant worker Calicut

\section{Differences between the Study Sites}

There were two key areas in which the responses by participants from Chirala and Calicut differed. First, a third of the FSW from Chirala reported occasionally using female condoms as an alternative to male condoms during their sexual transactions. If negotiations for male condoms with clients were unsuccessful, Chirala FSW would sometimes insert a female condom. This was often done surreptitiously when the client was otherwise distracted or occupied. FSW in Calicut did not report this same strategy, nor did they find it practical when probed on the issue given cost and availability constraints.

One person has said that they will offer 700 rupees without using the condoms. I have used female condoms with that partner...He didn't know [that a female condom was used]. He could not identify it.Female sex worker Chirala

Since, they [truck drivers] are going to all the sex workers, we don't know whether all the clients use condoms or not. Some will refuse to use condoms, so in this clinic I will take female condoms. It is better to have female condoms; they can be used without the clients knowing. I will tell the other sex workers also that these female condoms can be used without the clients knowing.-Female sex worker Chirala

Whoever says that they are not satisfied to use male condoms at this situation I will use female condoms but I will not say that I am using female condoms. They come to the stage when they become moody, while having sex I will put female condoms. Since they are in mood they will not ask why I am using the female condoms. If I say that I want to use female condoms they will remove the female condoms... While having sex they will know that I have used the female condoms and will ask "what is that?" and I will say that I have used female condoms. Then they will say that they will give 1000 rupees and not to use the female condoms. I will say that my health is the only important thing.-Female sex worker Chirala

The second key difference between sites was regarding reports of sex between men. In Calicut, MMW reported engaging in sexual exchanges with other men, including with other migrant workers. These sexual behaviors were sufficiently common to be reported by FSW as well. These behaviors were not reported by any Chirala participants.

Last time when we did this one guy among us was a person who didn't know that we do this kind of things [sex between men]. He also doesn't know how to go about it... There was a little hesitation for him to do it... The one person was ok with doing anal but the other person had some problem in doing it-it was his first experience-so when we did it for him blood came, so his interest was gone so we stopped and did oral sex.-Male migrant worker Calicut

To be frank, the majority of the people who are found here [Calicut] are all homosexual ones. Male to male performers we call it here as a code language: Cycling men and people who are asking for ' $\mathrm{W}$ '. It 
means those people are interested doing sex through the ass... They even tell us that they get horny when men perform sex with them, "If they can do whatever we ask them, why you women can't do the same to us? We will pay you the same amount that which we pay to those guys so why can't you do the same to us?"-Female sex worker Calicut

\section{Discussion}

The potential for South Indian FSW and MMW to serve as bridge populations for HIV to the general population makes them particularly important groups for AIDS prevention efforts. This study provides essential information about the context, motivation and perceived consequences of alcohol use and of sexual risk-taking in both of these groups as well as the role of alcohol and protection in their interactions, all of which has implications for HIV prevention efforts in these communities and for future research.

\section{Conclusions}

Most of the men interviewed in this study reported consuming alcohol prior to engaging in commercial sex, stating that alcohol gave them the courage to seek out sex workers and ask for non-traditional forms of sex. They also perceived alcohol as helping them prolong the sexual encounter, and overcome emotional distress. These findings echo those from earlier studies with men in Mumbai and wine shop patrons in Chennai [25, 27]. Other studies of male migrant workers in India and Mexico have attributed their higher rates of alcohol use and sexual risk to the living conditions and loneliness that workers endure while away from their wives [29, 39]. A further motivating risk factor are the socializing activities that take place within the peer group, including alcohol use, viewing of pornographic films and visiting bars and sex workers together with their migrant peers [28, 29].

MMW and FSW described a variety of consequences that resulted from the consumption of alcohol and influenced the sexual risk-taking taken by both partners. Both groups described a series of changes that took place after drinking, including different sexual behaviors, increased aggression and reduced condom use. After drinking, clients' tended to demand non-traditional sexual positions, which may reflect potential inhibitions present when sober and within the clients' regular, non-paying sexual relationship. Also, the more aggressive behavior of inebriated clients placed the sex workers at risk and the fear of violence affected the negotiation of condom use, sometimes derailing it altogether. Lastly, condom use was influenced both by the inebriation of one or both partners and by the availability of condoms at the time of the sexual encounter. Our results echo those found in a study among Canadian FSW where being pressured by a client into unprotected sex was associated, among other things, with client-perpetrated violence and servicing clients in cars and public spaces [40].

Regarding site differences, several FSW in Chirala reported using female condoms as an alternative to male condoms, in particular when the negotiation with their client had been unsuccessful. While the use of female condoms was restricted to respondents from Chirala, this finding could be due to regional differences in female condom promotion programs. Further, it is notable that male-to-male sexual behaviors were reported only by Calicut participants. The 2006 National Behavioral Surveillance Survey reports a greater prevalence of men indulging in sexual activities with a male partner in Kerala (7\%) than in Andhra Pradesh (2\%), among those who had ever heard of MSM activities [41], which corresponds to our findings. However, it is also possible that this difference in our study is at least partly due to a sampling artifact. In Calicut, some MMW were referred to this study by a local NGO that conducts outreach to local MSM, including migrants. While previous research has found a substantial number of MSM behaviors in Andhra Pradesh [42], none of our collaborating NGOs in Chirala currently conduct MSM outreach, which may have reduced the likelihood of such referrals.

\section{Implications for Future Interventions and Research}

The findings from this study suggest that Indian male migrant workers may benefit from some of the same interventions found effective for Mexican migrant workers in the United States, including the use of picture books and radio serials promoting responsible choices based on the experiences that migrant workers face. Interventions conducted with Mexican migrants in the United States used these media to provide HIV prevention information through stories where male farmer workers (a) use condoms with a sex worker, (b) abstain from sex with a sex worker and (c) infect their families with HIV as a result of unprotected sex with sex worker [39]. These interventions resulted in increased condom use among migrants visiting sex workers in two uncontrolled studies [39]. Adapting these interventions to reflect the experiences that Indian MMW face could help promote condom use, especially in situations where the migrant worker has been drinking.

It would also be beneficial to develop interventions that directly address the feelings of loneliness and isolation reported by the MMW. Interventions that focus on 
alternative forms of socialization among men that do not involve alcohol have been shown to be successful in other settings. The Mpowerment Project launched in Oregon and California successfully reduced high-risk behaviors in young gay men by establishing peer outreach and a community center that offered social events designed to appeal to different segments of the local gay male community, such as parties, picnics and other outdoor activities [43, 44]. Adapting this and other similar interventions to engage MMW in their communities would be another way to address alcohol consumption and its attendant risky behaviors. Another potential avenue for addressing loneliness among MMW that could also be explored are high tech strategies, such as VoIP or Skype, to promote more regular contact between migrants and their families.

In order to address female sex workers' motivations for alcohol consumption, future research needs to explore in more depth the reasons why FSW feel the need to numb themselves prior to their sexual transactions. If reasons center on depression or shame, interventions that include mental health referrals would be appropriate. If FSW are using alcohol because they feel ashamed and want to leave the sex trade, referrals to vocational training programs may be useful. Lastly, future research needs to explore whether the perceived cooling effect of alcohol reported by our participant is wide-spread, in which case it should be addressed in the knowledge component of future risk reduction interventions.

Many FSW reported avoiding alcohol prior to sexual transactions as a type of protective mechanism in these types of uncomfortable situations with clients. In addition to this strategy, it might be helpful to include intervention activities that address the potential for violence and sexual risk associated with alcohol consumption. Skills-based training for FSW needs to have a dual focus on defusing or escaping volatile situations as well as condom negotiations when dealing with inebriated clients. It may be useful to build peer networks and educate FSW about community resources to improve their safety and limiting their HIV risk. As for MMW, it is important for future research to focus on improving their communication skills around requesting non-traditional sexual behaviors or positions while sober. Further, interventions that address the issues faced by migrant workers returning home are needed, especially in the context of their marital relationship.

The results show that condoms had to be on hand immediately preceding intercourse for either partner to attempt to use them. To address this issue, it is crucial that prevention programs increase condom distribution and availability in venues close to the transactional encounters. In this study, participants listed a variety of locations for sexual encounters, including side roads, empty houses, bushes near bus and train stations as well as brothels and lodges. Many of the locations where FSW and MMW engage in commercial sex are transient and informal and further research is needed to explore how condoms could be made available there. However, condoms could immediately be distributed to lodges and transportation stations, perhaps by engaging lodge owners as partners in this prevention effort.

While the use of female condoms was restricted to respondents from Chirala, this finding could be due to regional differences in previous female condom promotion programs, suggesting that female condoms might present a feasible alternative to male condoms and a supplement to current HIV prevention efforts in both locations. Additional research is needed to explore their acceptability and feasibility in Calicut.

Reports of same sex behaviors among male migrant workers in Calicut point toward the need for more research to elucidate the patterns of MSM behavior in these communities. Furthermore, HIV prevention programs should be re-focused to include messages that condoms are needed with all types of sexual partners. To guide such campaigns, future studies of Indian MMW should explore their perceptions of risk during unprotected sex with both male and female transactional and non-transactional partners as such information is not currently available in the literature.

\section{Limitations}

Two issues that limit the generalizability of the findings should be noted. First, the participants in this study may not represent the entire MMW and FSW communities in their respective cities. Participants that did not speak Telugu, Tamil or Malayalam were excluded, which prevented us from interviewing migrant men who came from other states, such as Bihar. In addition, no white-collar migrant men were interviewed, limiting our generalizations to migrant men in blue collar jobs. Further, contract migrants that work in courier offices or at the airport were also excluded due to limits on access. Lastly, it should be noted that the men interviewed for this study may not represent non-migrant clients of FSW in these regions. In addition, women who engage in commercial sex based out of their homes, and those who had not done sex work in the past 3 months are not represented in this study.

A second limitation of this study is that participants were recruited through snowball sampling and key informants who were a part of contact networks of the partner organizations in each study site. While every attempt was made to obtain a cross-section of these populations, it is possible that affiliation or knowledge of either of the partner organizations may have functioned as a selfselection characteristic in either of the study groups. 


\section{Summary}

The data presented here on alcohol consumption and sexual risk-taking among South Indian FSW and MMW illuminate essential elements in the commercial sex encounter in these settings. MMW tend to drink prior to seeking out commercial sex because it gives them courage and helps them last longer during the sexual encounter, whereas FSW often remain sober intentionally in order to avoid difficult or violent situations with clients. Alcohol use in these partner groups was linked to requests of non-traditional sexual behaviors by MMW, violent and aggressive behavior from the men towards the sex workers, and reduced likelihood of condom use. Two important site differences were worth noting: the use of female condoms among sex workers in Chirala and the reports of MSM behaviors in Calicut. These results have important implications both for future research and future interventions to reduce the risk of acquiring HIV in these vulnerable, potential bridge populations.

Acknowledgments This research was supported by research grant 5RO1AA15298 from the National Institute on Alcohol Abuse and Alcoholism (NIAAA). Special thanks are extended to our field research teams and to all of the participants who so generously shared their stories with us for this study.

Open Access This article is distributed under the terms of the Creative Commons Attribution Noncommercial License which permits any noncommercial use, distribution, and reproduction in any medium, provided the original author(s) and source are credited.

\section{References}

1. National AIDS Control Organisation. UNGASS country progress report 2008-India. New Delhi: National AIDS Control Organisation; 2008.

2. National AIDS Control Organisation. HIV sentinel surveillance and HIV estimation in India 2007-a technical brief. New Delhi: National AIDS Control Organisation; 2007.

3. Mohan D, Sharma H. Alcohol and culture in India. In: Heath D, editor. International handbook on alcohol and culture. Westpost: Greenwood Publishing Group; 1995.

4. Saxena S. Alcohol related problems in India: need for policy oriented approach. In: Murthy R, editor. Mental health in India 1950-2000: essays in honour of Professor N.N. Wig. Bangalore: PAMH; 2001. p. 54-9.

5. WHO. Surveys of drinking patterns and problems in seven developing countries: WHO monograph on alcohol epidemiology in developing countries. Geneva: WHO; 2000.

6. Benegal V. India: alcohol and public health. Addiction. 2005;100(8):1051-56.

7. Deb P, Jindal R. Drinking in rural areas: a study in selected villages of Punjab in wake of green revolution. Ludhiana: Punjab Agricultural University; 1974.

8. Lal B, Singh G. Alcohol consumption in Punjab. Indian J Psychiatry. 1978;20:212-6.
9. Sethi B, Trivedi J. Drug abuse in a rural population. Indian J Psychiatry. 1979;21:211-6.

10. Advani G, Sharma H, Sundaram K, Mohan D. Recent trends in alcohol and drug abuse in India. In: Mohan D, Sethi H, Tongue E, editors. Current research in drug abuse in India. New Delhi: AIIMS; 1981.

11. Mohan D, Sharma H, Sundaram K, Advani G. Prevalence and pattern of alcohol abuse in rural community and its correlation with psycho social sequelae. New Delhi: Ministry of Social Welfare; 1981.

12. Mohan D, Sharma H, Sundaram K, Neki J. Pattern of alcohol consumption of rural Punjab males. Indian $\mathrm{J}$ Med Res. 1980;72:702-11.

13. Mohan D, Sundaram K, Sharma H. A study on health education, intervention on non-medical use of drugs in the community. New Delhi: Indian Council of Medical Research; 1983.

14. Varma V, Singh A, Singh S, Malhotra A. Extent and pattern of alcohol use and alcohol-related problems in North India. Indian J Psychiatry. 1980;22:331-7.

15. Mohan D. Rapid assessment survey on alcohol tobacco and other substances in districts of Aizawl (Mizoram), Kohima (Nagaland) and Darjeeling (West Bengal). New Delhi: Drug Dependence Treatment Center, AIIMS; 1999.

16. Mohan D. Rapid assessment survey on alcohol tobacco and other substances in districts of Thobul (Manipur), Mandsaur (Madhya Pradesh) and Barabanki (Uttar Pradesh). New Delhi: Drug Dependence, Treatment Center AIIMS; 1999.

17. Tripathi B. Alcohol use and sexual risk behaviors across cultures: report on Focus Group Discussions, Interviews and Observations-India. WHO, All India Institute of Medical Sciences; 2003.

18. Ministry of Social Justice and Empowerment. The extent, pattern and trends of drug abuse in India-national survey. New Delhi, India: United Nations Office on Drugs and Crime; 2004.

19. Cooper ML. Alcohol use and risky sexual behavior among college students and youth: evaluating the evidence. J Stud Alcohol. 2002;(Suppl 14):101-117.

20. Cooper ML. Does drinking promote risky sexual behavior? A complex answer to a simple question. Curr Dir Psychol Sci. 2006;15(1):19-23.

21. Leigh BC, Stall R. Substance use and risky sexual behavior for exposure to HIV. Issues in methodology, interpretation, and prevention. Am Psychol. 1993;48(10):1035-45.

22. Baliunas D, Rehm J, Irving H, Shuper P. Alcohol consumption and risk of incident human immunodeficiency virus infection: a meta-analysis. Int J Public Health. 2010;55(3):159-66.

23. Fisher JC, Bang H, Kapiga SH. The association between HIV infection and alcohol use: a systematic review and meta-analysis of African studies. Sex Transm Dis. 2007;34(11):856-63.

24. Leigh BC. Alcohol and condom use: a meta-analysis of eventlevel studies. Sex Transm Dis. 2002;29(8):476-82.

25. Sivaram S, Srikrishnan AK, Latkin $C$, et al. Male alcohol use and unprotected sex with non-regular partners: evidence from wine shops in Chennai, India. Drug Alcohol Depend. 2008;94 (1-3):133-41.

26. Go VF, Solomon S, Srikrishnan AK, et al. HIV rates and risk behaviors are low in the general population of men in southern India but high in alcohol venues-results from 2 probability surveys. J Acquir Immune Defic Syndr. 2007;46(4):491-7.

27. Schensul SL, Mekki-Berrada A, Nastasi BK, Singh R, Burleson JA, Bojko M. Men's extramarital sex, marital relationships and sexual risk in urban poor communities in India. J Urban Health. 2006;83(4):614-24.

28. Madhivanan P, Hernandez A, Gogate A, et al. Alcohol use by men is a risk factor for the acquisition of sexually transmitted 
infections and human immunodeficiency virus from female sex workers in Mumbai, India. Sex Transm Dis. 2005;32(11):685-90.

29. Saggurti N, Verma RK, Jain A, et al. HIV risk behaviours among contracted and non-contracted male migrant workers in India: potential role of labour contractors and contractual systems in HIV prevention. Aids. 2008;22:S127-36. (Dec).

30. Singh YN, Malaviya AN. Long distance truck drivers in India: HIV infection and their possible role in disseminating HIV into rural areas. Int J STD AIDS. 1994;5(2):137-8.

31. National AIDS Control Organisation. National behavioral surveillance-summary. New Delhi: National AIDS Control Organisation; 2006.

32. Goldenberg SM, Cruz MG, Strathdee SA, Nguyen L, Semple SJ, Patterson TL. Correlates of unprotected sex with female sex workers among male clients in Tijuana, Mexico. Sex Transm Dis. 2010;37(5):319-24.

33. Bryant KJ. Expanding research on the role of alcohol consumption and related risks in the prevention and treatment of HIV/ AIDS. Subst Use Misuse. 2006;41(10-12):1465-507.

34. Patterson TL, Goldenberg S, Gallardo M, et al. Correlates of HIV, sexually transmitted infections, and associated high-risk behaviors among male clients of female sex workers in Tijuana, Mexico. Aids. 2009;23(13):1765-71.

35. UNAIDS, WHO, UNICEF. Epidemiological fact sheet on HIV and AIDS-India. Geneva: UNAIDS; 2008.

36. National Institute of Health and Family Welfare, National AIDS Control Organisation. Annual HIV sentinel surveillance country report. New Delhi: National Institute of Health and Family Welfare and National AIDS Control Organisation; 2006.

37. National AIDS. Control organisation. Annual report NACO 2008-2009. New Delhi: NACO; 2008.

38. National AIDS Control Organisation. HIV fact sheets-based on HIV sentinel surveillance data in India, 2003-2006. New Delhi: National AIDS Control Organisation; 2007.

39. Organista KC, Carrillo H, Ayala G. HIV prevention with Mexican migrants: review, critique, and recommendations. J Acquir Immune Defic Syndr. 2004;37(Suppl 4):S227-39.

40. Shannon K, Strathdee SA, Shoveller J, Rusch M, Kerr T, Tyndall MW. Structural and environmental barriers to condom use negotiation with clients among female sex workers: implications for HIV-prevention strategies and policy. Am J Public Health. 2009;99(4):659-65.

41. National AIDS Control Organisation. National behavioral surveillance survey—general population. New Delhi: National AIDS Control Organisation; 2006.

42. Dandona L, Dandona R, Gutierrez JP, Kumar GA, McPherson S, Bertozzi SM. Sex behaviour of men who have sex with men and risk of HIV in Andhra Pradesh, India. Aids. 2005;19(6):611-9.

43. Kegeles SM, Hays RB, Coates TJ. The Mpowerment project: a community-level HIV prevention intervention for young gay men. Am J Public Health. 1996;86(8):1129-36.

44. Kegeles SM, Hays RB, Pollack LM, Coates TJ. Mobilizing young gay and bisexual men for HIV prevention: a two-community study. Aids. 1999;13(13):1753-62. 